\title{
Recommendations for the Management of Behavioral and Psychological Symptoms of Dementia
}

\author{
Nathan Herrmann
}

\begin{abstract}
Background: The behavioral and psychological symptoms of dementia (BPSD) are common, serious problems that impair the quality of life for both patient and caregiver. In order to provide recommendations based upon the best available evidence, a qualitative literature review was performed. Methods: A search of the English language medical literature published between 1966 and 2000 was performed. The quality of the studies was assessed by considering the subjects, trial design, analysis and results. Final recommendations were based upon the quality of available evidence. Results: The management of BPSD begins with a thorough assessment to search for underlying causes of behaviour change. Concomitant medical illness should be treated and sensory impairment ameliorated. Nonpharmacological approaches should be instituted prior to medication use. These interventions include music, light, changes in level of stimulation and specific behavioral techniques. Antipsychotics are the best studied pharmacological intervention for agitation and aggression and have demonstrated modest but consistent efficacy. Antidepressants such as trazodone and selective serotonin re-uptake inhibitors, as well as anticonvulsants such as carbamazepine and valproic acid have also demonstrated efficacy. Benzodiazepines can be used for short-term treatment as p.r.n. agents when necessary. Pharmacotherapy must be monitored closely for both effectiveness and side effects, with consideration of medication withdrawal when appropriate. Conclusion: The management of BPSD can significantly improve the quality of life for the patient and caregiver. Their assessment and management are essential components of the treatment of dementia.
\end{abstract}

RÉSUMÉ: Recommandations pour la prise en charge des symptômes comportementaux et psychologiques de la démence. Introduction: Les symptômes comportementaux et psychologiques de la démence (SCPD) sont des problèmes fréquents et sérieux qui altèrent la qualité de vie du patient et de l'aidant. Une revue qualitative de la littérature a été effectuée afin de fournir des recommandations basées sur les données scientifiques disponible. Méthodes: Une recherche de la littérature médicale de langue anglaise publiée entre 1966 et 2000 a été effectuée. La qualité des études a été évaluée en considérant les sujets, le plan de l'étude, l'analyse et les résultats. Les recommandations finales ont été fondées sur la qualité des observations disponibles. Résultats: La prise en charge des SCPD commence par une évaluation minutieuse pour rechercher les causes sous-jacentes du changement de comportement. Les maladies concomitantes devraient être traitées et les déficits sensoriels améliorés. Des approches non pharmacologiques devraient être instituées avant de prescrire une médication. Ces interventions incluent la musicothérapie, la photothérapie, les changements dans le niveau de stimulation et l'utilisation de techniques comportementales spécifiques. Les antipsychotiques constituent l'intervention pharmacologique la mieux étudiée pour traiter l'agitation et l'agressivité. Ils ont démontré une efficacité modeste mais constante. Les antidépresseurs tels le trazodone et les inhibiteurs sélectifs de la recaptation de la sérotonine de même que des anticonvulsivants tels la carbamazépine et l'acide valproïque sont également efficaces. Les benzodiazépines peuvent être utilisées à court terme, p.r.n. La pharmacothérapie doit être surveillée étroitement tant au point de vue de son efficacité que de ses effets secondaires, avec réévaluation de sa pertinence. Conclusion: La prise en charge des SCPD peut améliorer significativement la qualité de vie du patient et des aidants. Leur évaluation et leur prise en charge sont des composantes essentielles du traitement de la démence.

Can. J. Neurol. Sci. 2001; 28: Suppl. 1 - S96-S107

The behavioral and psychological symptoms of dementia (BPSD) include delusions, hallucinations, misidentifications, agitation, wandering, pacing, restlessness, disinhibition, apathy, negativism, emotional lability, depression, anxiety, sleep disturbance and sexually inappropriate behaviours. ${ }^{1}$ While not included as diagnostic criteria for dementia by DSM-IV ${ }^{2}$ or the NINCDS-ADRDA, ${ }^{3}$ behaviours such as paranoia, depression, euphoria and apathy were recognized by Alzheimer in the initial description of the illness that bears his name. ${ }^{4}$ Historically, the focus on BPSD began only recently, prompted by an early study by Rabins et al, ${ }^{5}$ who interviewed caregivers of patients with dementia. While these behaviours were noted in $50-90 \%$ of patients, caregivers considered physical aggression the most serious problem that they encountered, rating it more frequently as a serious problem than the memory disturbance itself. The significance of BPSD was recently endorsed by both the United States Alzheimer's Association ${ }^{6}$ and the International Psychogeriatric Association ${ }^{1}$ as research priorities.

The phenomenology and prevalence of BPSD have been

From the Division of Geriatric Psychiatry, University of Toronto, and Sunnybrook \& Women's College Health Sciences Centre, North York, ON

Reprint requests to: Nathan Herrmann, Division of Geriatric Psychiatry, Sunnybrook Health Science Centre, 2075 Bayview Avenue, Room FG20, North York, ON M4N 3M5 Canada. 
documented in numerous studies, ${ }^{7-12}$ with estimates of frequency of up to $90 \%$ of patients at some point during the course of the illness. ${ }^{6}$ While likely most common in long-term care institutions, ${ }^{13-15}$ they occur frequently in outpatient populations and community samples as well. ${ }^{8,16}$ Many of these behaviours are most prevalent during the moderate and moderately severe stages of dementia, ${ }^{8}$ though symptoms such as agitation, apathy and aberrant motor behaviour may continue to increase with progressive cognitive decline. ${ }^{17,18}$ BPSD are common in both Alzheimer's disease (AD) ${ }^{19-22}$ and vascular dementia, ${ }^{23}$ and may occur even more frequently and earlier in the course of the frontotemporal dementias ${ }^{24}$ and dementia with Lewy bodies (DLB). ${ }^{25}$ Besides representing a primary source of stress for caregivers, ${ }^{6}$ behaviours such as agitation and aggression can contribute to the institutionalization of demented patients. ${ }^{26,27}$ Conversely, even modest improvements in these behaviours can result in significant improvements in the quality of life for both patient and caregiver. ${ }^{28}$

\section{METHODS}

A comprehensive search of the medical literature using Medline (1996-2000) and Embase (1974-2000) databases was conducted. Key words included: dementia, behavior, behavior therapy, drug therapy, antipsychotic agent and antidepressant agent. Manual cross-referencing of bibliographies from all papers and recent reviews was also done. The quality of the studies was assessed by considering the subjects, trial design, analysis and results. Final recommendations were based upon best available evidence utilizing criteria developed by the Canadian Task Force on the Periodic Health Examination. ${ }^{29}$ An earlier version of this paper served as a source document for the Canadian Consensus Conference on Dementia. ${ }^{30}$ These recommendations do not include the management of depression and depressive symptoms which have been dealt with in another paper in this series.

\section{Management}

\section{Assessment}

The management of BPSD requires a multifaceted plan which includes assessment and diagnosis, ensuring the safety of the patient, caregiver and co-residents, choosing and monitoring target symptoms, instituting environmental and behavioral interventions and initiating and monitoring pharmacotherapy if necessary. Because patients with dementia are highly susceptible to delirium, the assessment of new onset BPSD must include a physical examination and appropriate laboratory investigations to rule out concomitant medical illness (for example, urinary tract infections). Even chronic medical conditions (for example, arthritis) should be optimized, as stimuli such as pain, constipation and shortness of breath may cause agitation, restlessness and aggression. Optimization should also include hearing and vision, as sensory impairment can lead to behaviours such as agitation and paranoia. ${ }^{31,32}$ The importance of considering sensory impairment was recently highlighted in a study comparing $\mathrm{AD}$ patients with and without visual hallucinations. ${ }^{33}$ Visual acuity was significantly more impaired in patients with hallucinations and none of the patients who presented with visual hallucinations had normal acuity. When vision was improved by refraction in a portion of those patients with visual hallucinations, most of these were free of hallucinations on follow-up. A review of concomitant medications is essential as at least one study has suggested that $16 \%$ of demented patients who presented to a regional psychogeriatric service with agitation, aggression, confusion, or disorientation had causes that were attributable to medications. ${ }^{34}$

As part of the initial assessment, safety issues must be considered. BPSD can increase the risk of suicide as well as physical aggression and violence. While caregiver and coresident safety need to be assessed, behaviours such as perseverative screaming and intrusive wandering may place the patient at risk from physical harm by other residents whom they disturb. Finally, while wandering out of a safe, protected environment is potentially dangerous, wandering can also increase the risk of falls, particularly when there is a pre-existing gait disturbance, or the environment contains dangerous obstacles such as throw rugs, poor lighting or low tables.

The choice and characterization of target symptoms is a frequently overlooked but important aspect of management. Along with the caregiver, the clinician should document the nature, intensity, frequency, precipitants and consequences of each behaviour. ${ }^{35}$ While numerous scales for BPSD have been designed, all have relative strengths and weaknesses, ${ }^{36}$ and there is no single scale that has attained the almost universal acceptance of the Mini Mental State Examination ${ }^{37}$ for cognition. Several useful scales with documented validity and reliability include the Behavioral Pathology in Alzheimer's Disease Rating Scale ${ }^{8}$ the Neuropsychiatric Inventory, ${ }^{38}$ and the Cohen-Mansfield Agitation Inventory. ${ }^{39,40}$ The systematic documentation of behaviours provides for a more accurate assessment of the effectiveness of interventions, as well as engages the caregiver in the management plan even prior to initiation of therapy. The value of systematic behavioral assessments has also been demonstrated in a study by Nilsson et al. ${ }^{41}$ In an attempt to demonstrate the reliability and validity of a newly designed scale to measure aggression in the elderly, these investigators asked staff on long-term psychogeriatric wards to use the scale for six weeks. The scale required staff to document the nature of the aggression, the antecedents and the consequences. ${ }^{42}$ The number of aggressive incidents decreased from 91 at baseline to 16 at week six, without any other changes in management. This structured approach to observation likely allowed the staff to recognize, anticipate and avoid provocative events.

\section{Nonpharmacological interventions}

Nonpharmacological interventions for BPSD include a variety of treatments such as environmental modifications, light therapy, music therapy, pet therapy, activity therapy (for example, exercise, dancing, social interaction, etc.) and specific behavioral techniques. ${ }^{43}$ Extensive clinical experience with these techniques support their use, with some investigators describing them as possibly more effective and better tolerated than pharmacological approaches. ${ }^{44}$ Unfortunately, there are almost no large, randomized, controlled trials of these techniques, though numerous, small studies with intrasubject designs do exist. $^{35,45}$ A recent systematic review of the psychosocial approaches to BPSD found 43 studies which included at least 
some measure of behavior pre- and postintervention. ${ }^{46}$ There were only five randomized controlled trials and only one study which was rated as having strong validity. Weakness of study design included small numbers of subjects, poorly characterized study participants, inadequate data collection, high drop-out rates and insufficient statistical analysis. As an example, the only study rated as having strong validity utilized a behavior management program to modify repetitive verbalizations in community-dwelling patients with AD. ${ }^{47}$ This well-designed, carefully documented study included only seven subjects and seven controls. The only large, randomized trial examined a multimodal treatment approach for 89 nursing home residents, which included a daily, structured activities program, as well as staff education and guidelines for psychotropic use. Following six months of these interventions, $29 \%$ of treatment subjects exhibited behavioral problems compared with $51 \%$ of controls. While subjects in both groups received psychotropics, controls were more than twice as likely to receive antipsychotics or be physically restrained compared with subjects in the treatment group. ${ }^{48}$

Changes to the level of stimulation can have varying effects on patients with dementia and disturbed behaviour. While studies examining methods to increase stimulation by use of activity groups, exercise and social interaction have demonstrated positive results, ${ }^{43,48}$ other studies suggest reduced stimulation may decrease agitation and other problematic behaviours. ${ }^{49}$ Increasing the level of stimulation may occasionally have adverse effects. In a small, case-control study, when subjects with dementia participated in twice weekly group sessions aimed at increasing emotional and intellectual stimulation, improvements on some measures of cognition were noted but there was also a significant increase in restlessness in the treatment group..$^{50}$

Other environmental manipulations include the use of sound and light. Several studies suggest that a variety of music interventions can decrease agitation. ${ }^{51-54}$ Similarly, audio tapes of environmental "white noise" (sounds of gentle oceans and mountain streams) can also significantly reduce agitation. ${ }^{55}$ Finally, several studies have suggested that interventions with bright light might improve sleep-wake cycle disturbances and other behaviours. ${ }^{56,57}$ For example, a recent study administered one hour of bright light every morning using a 10,000 lux full spectrum lamp at three feet. These patients were seated in front of the lamp in a quiet room, with a nurse who reminded them to keep their eyes open for the entire treatment period. Only eight of 15 patients could complete the full four week treatment period but the average number of nocturnal sleep hours increased significantly from 6.4 to 8.1 hours/night. No other changes in behavior could be documented. ${ }^{58}$

Behavioral techniques have been defined as interventions that require clinical problems to be operationalized, emphasize learning experience to modify behaviour, require empirical treatment evaluation, are directive and active in nature and involve use of another person to help achieve therapeutic change. ${ }^{45}$ After systematically documenting behaviours, their antecedents and consequences as described previously, caregivers intervene with a variety of techniques such as differential reinforcement of other behaviours, extinction and time-out. ${ }^{43,59}$ Preliminary studies suggest these techniques can effectively decrease aggression and disruptive behaviours. ${ }^{60,61}$ While all these interventions are promising, well-designed and controlled trials are required to clearly document their efficacy. ${ }^{62}$

\section{Pharmacotherapy}

\section{General principles}

The use of psychotropic medications for the treatment of BPSD can be extremely helpful, especially when patients have failed to respond to environmental and behavioral interventions. ${ }^{63,64}$ While pharmacotherapy should not be considered a "treatment of last resort", there is growing concern that these medications are over-used, misused and administered by staff who are unaware of their expected benefits and potential side effects. ${ }^{65}$ Psychotropic medications for BPSD are used frequently in hospitals, ${ }^{66}$ long-term care facilities ${ }^{65,67,68}$ and the community. ${ }^{69}$ In the United States, concerns about over-use and misuse has led to the enactment of the Omnibus Reconciliation Act (OBRA-87), which established guidelines for the appropriate use of these medications. ${ }^{70,71}$

There are numerous age-associated changes that affect the pharmacokinetics and pharmacodynamics of psychotropic medications. ${ }^{72}$ For many psychotropics, it will take longer to reach steady state, half-life will be lengthened and elimination will take longer. Elderly patients often require lower dosages and are most susceptible to side effects. Co-morbid illness may increase the potential for adverse events and concomitant medications may increase the potential for drug interactions. A specific concern involves the anticholinergic effects of many psychotropics such as antipsychotics and some antidepressants. In elderly patients with dementia, anticholinergic effects can worsen confusion, ${ }^{73}$ precipitate delirium, ${ }^{74}$ exacerbate preexisting cardiac disease and lead to urinary retention in patients with prostatic hypertrophy. Psychotropic medications with anticholinergic properties may also counteract therapy with cognitive enhancers such as cholinesterase inhibitors and acetylcholine agonists.

Following documentation of specific target behaviours and choosing a psychotropic medication with the caveats noted previously, therapy should be initiated at low dosages with increases every three to seven days if necessary. Besides monitoring for effectiveness, adverse effects on cognition, function and gait, as well as excess sedation and changes in blood pressure (orthostatic hypotension) should be documented. The appropriate minimum length of a pharmacotherapeutic trial has not been established but range from two to four weeks for certain medications (for example, antipsychotics, benzodiazepines) to four to eight weeks for others (for example, beta blockers, anticonvulsants, antidepressants). Once patients have responded to a pharmacotherapy, periodic attempts to reduce or withdraw the medications are recommended, though the specific timing of such withdrawal attempts is not supported by data from clinical trials. While a number of antipsychotic discontinuation studies have been published, ${ }^{70,75-80}$ none were randomized, placebo-controlled, outcome was often insufficiently documented and duration of follow-up was short. These studies suggest, however, that at least for some patients, antipsychotic discontinuation is possible and can result in improvements in mood, cognition and functioning. Similar results have also been 
noted with benzodiazepine discontinuation. ${ }^{81}$ Finally, the specific target symptoms for which pharmacotherapy was prescribed may ultimately determine when, and if, to attempt taper and withdrawal. In a large, naturalistic observational study of mild to moderate AD, Devanand et $\mathrm{al}^{82}$ prospectively followed 235 patients over five years. Wandering and agitation were the most persistent problems, delusions and hallucinations were intermediate and depression was rarely persistent. Physical aggression was infrequent (likely due to the mild to moderate nature of the illness in this population) but the authors caution this behaviour not only increased in frequency throughout the observation period but may also become more persistent in the moderate to severe stages of the illness.

There are several popular treatment algorithms for the pharmacotherapy of BPSD that are purportedly based upon a "rational" approach to management. ${ }^{83-85}$ For example, Yudofsky et $\mathrm{al}^{85}$ have recommended the use of antipsychotics for aggression associated with psychotic symptoms, carbamazepine for aggression with seizures, lithium for aggression with mood symptoms, buspirone for aggression with anxiety and beta blockers for chronic aggression. While such recommendations appear "rational", there are insufficient data from clinical trials in patients with dementia to support the use of such algorithms. Studies have rarely been designed to examine the differential effects of pharmacotherapy on specific behaviours but more commonly have focussed on broader symptom complexes such as "agitation." Recommendations from this review will therefore be derived from an evidence-based approach to literature.

\section{Antipsychotics}

The best studied pharmacological intervention for BPSD is typical antipsychotic (neuroleptic) medication ${ }^{63,64}$ (Table 1). In a meta-analysis of well-designed controlled trials published until 1997, these medications attained significantly better improvement rates of $61 \%$ compared with $34 \%$ for placebo. ${ }^{86}$ Since that review, only one further randomized, placebocontrolled trial has been published. ${ }^{87}$ In that study "standard" dose haloperidol (2-3 mg/day) was significantly better than "low" dose haloperidol (0.5-0.75 mg/day) or placebo for the treatment of psychosis and psychomotor agitation in AD. Response rates ranged from 55-60\% with standard doses, 25$35 \%$ with low doses of haloperidol, to $25-30 \%$ with placebo. While these studies demonstrate consistent but often modest improvement in behaviour, typical antipsychotics are unfortunately associated with prominent side effects including sedation, orthostatic hypotension, anticholinergic effects and extrapyramidal effects. A recent study confirmed the significant risk for developing parkinsonism in patients with dementia, even when treated with very low dosages of typical antipsychotics. ${ }^{88}$ There is also some concern that typical antipsychotics may increase the rate of cognitive decline in patients with $\mathrm{AD}^{89}$ and hasten mortality in patients with LBD..$^{90}$

The available atypical antipsychotics (clozapine, risperidone, olanzapine, quetiapine) offer significant theoretical advantages over typical antipsychotics in view of their tendency to produce fewer extrapyramidal effects. There are several small case series describing the use of clozapine for BPSD, though significant side effects including falls, bradycardia, delirium and possibly an increased risk for the development of leukopenia limit its usefulness. ${ }^{91-93}$ Several case reports suggest that olanzapine, in doses between 2.5 and $10 \mathrm{mg} /$ day, can improve a variety of behaviors including agitation, aggression and psychosis in patients with $\mathrm{AD}$ and LBD. ${ }^{94,95}$ These reports, however, raise concerns about the precipitation of delirium and worsened

Table 1: Selected Antipsychotics for BPSD

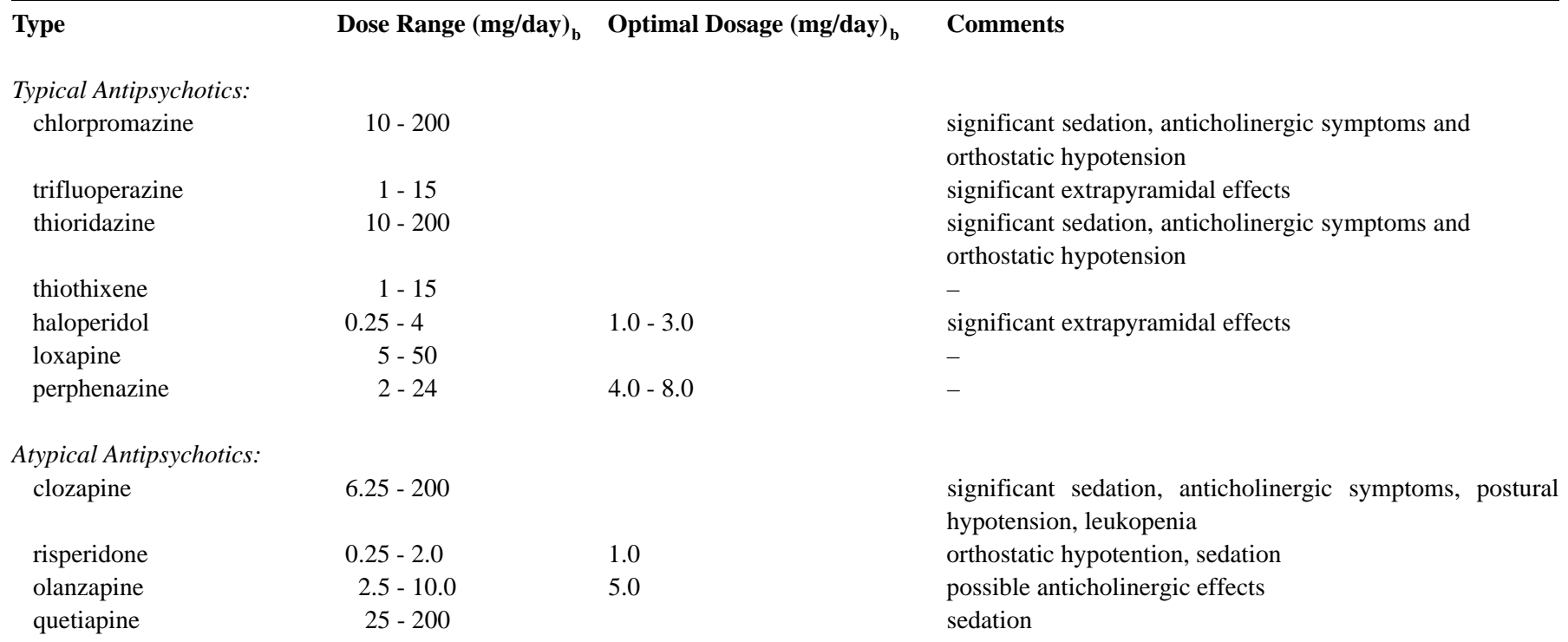

a - Table modified from Herrmann N, Lanctôt K, Naranjo C. Behavioural disorders in demented elderly patients: current issues in pharmacotherapy. CNS Drugs 1996; 6(4):280-30. Reprinted with permission.

b - Dosages based upon trials for BPSD 
Table 2: Selected Nonantipsychotic Medication for BPSD

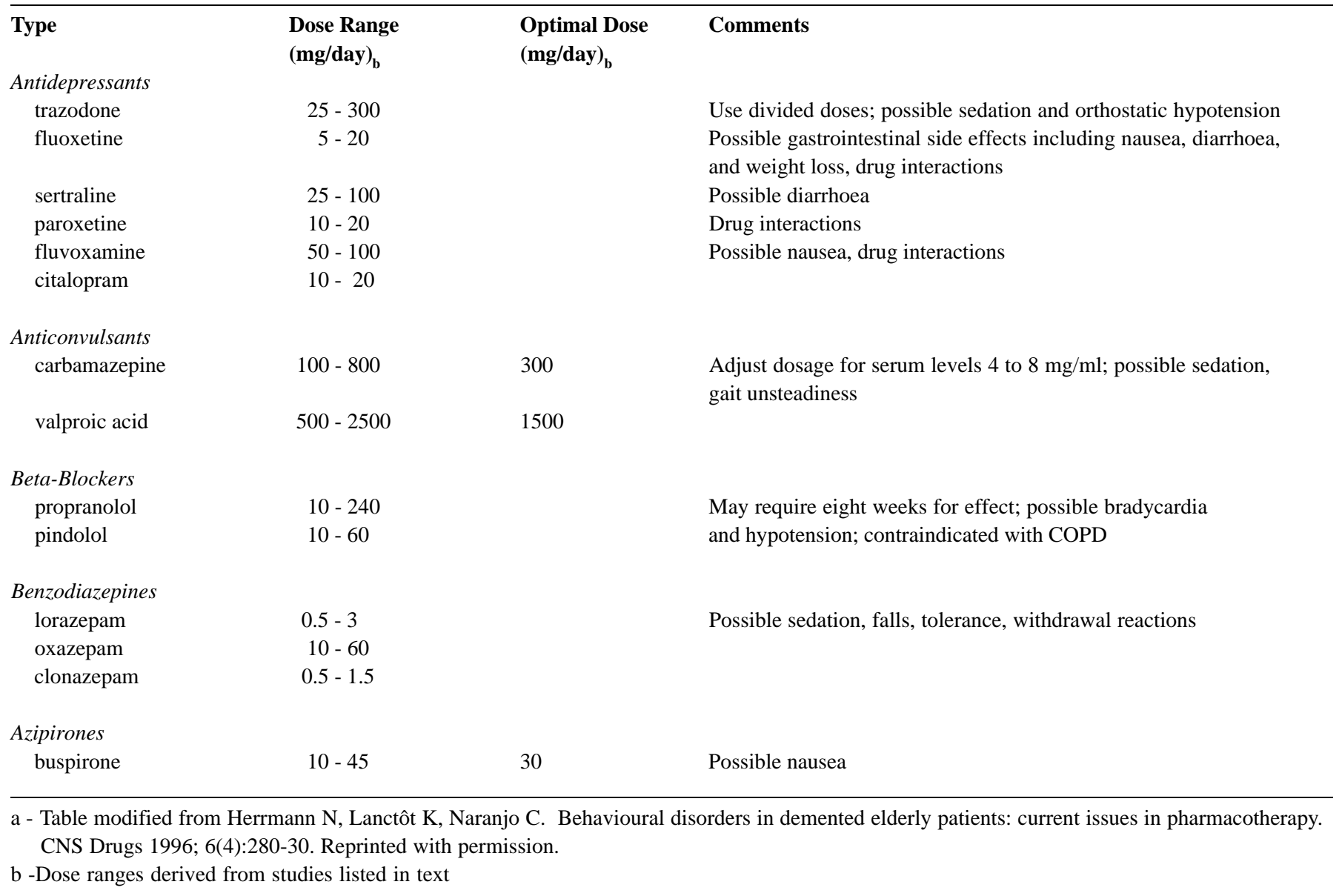

cognition in a proportion of patients, possibly due to olanzapine's anticholinergic effects which have been documented in vitro. ${ }^{96}$ Data from a large randomized placebocontrolled trial of olanzapine for BPSD in AD have recently been published, suggesting that at the optimal dose of $5 \mathrm{mg} /$ day, olanzapine was more effective than placebo treating agitation, delusions and hallucinations, with extrapyramidal symptoms no different compared to placebo. ${ }^{97}$ Of note, at this dose, there was no significant increase in central or peripheral anticholinegic effects compared with placebo. Less data are available on quetiapine, though results from a one year open-label study of 78 patients with AD suggest significant improvements in behaviors such as hostility. ${ }^{98} \mathrm{~A}$ randomized, placebo-controlled trial of quetiapine for BPSD has also recently been completed.

The best evidence for the use of atypical antipsychotics for BPSD is with risperidone. There is a large number of case series which document its use. ${ }^{99-102}$ In low doses, risperidone appears effective and well-tolerated. Side effects have included sedation, orthostatic hypotension and extrapyramidal symptoms which are clearly dose related. The results of two large, multicentre, randomized, placebo-controlled studies of risperidone for the treatment of BPSD have been published. In a fixed-dose study of risperidone comparing $0.5 \mathrm{mg}, 1 \mathrm{mg}$ and $2 \mathrm{mg}$ per day with placebo in 625 patients with dementia, significantly greater improvement was noted in patients receiving 1-2 $\mathrm{mg}$ of risperidone on total behavioral scores, as well as subscales assessing psychosis and aggression. The frequency of side effects was similar to placebo in the group receiving $1 \mathrm{mg}$ per day, with increased extrapyramidal symptoms in the group receiving $2 \mathrm{mg}$ per day. ${ }^{103}$ In a second study of 344 patients with dementia, a flexible dose of risperidone was compared with placebo as well as an active control, haloperidol. At an average dose of $1.1 \mathrm{mg}$ per day, risperidone was significantly better than placebo at reducing total behavioral scores and aggression. The efficacy of risperidone was equal to that of $1.2 \mathrm{mg}$ per day of haloperidol, though extrapyramidal side effects were significantly more frequent in the haloperidol-treated patients. ${ }^{104}$

While controlled trials, such as those described previously, are beginning to document the expected benefit of lower acute extrapyramidal symptoms with atypical antipsychotics, their potential lower association with tardive dyskinesia may be even more impressive. Randomized controlled trials of long-term use are not yet available, however a prospective nine-month longitudinal study of elderly outpatients, many with dementia, 
compared the incidence of emergent tardive dyskinesia in a group treated with risperidone (median dose $1.0 \mathrm{mg}$ ) and haloperidol (median dose $1.0 \mathrm{mg}$ ). Over $30 \%$ of the haloperidoltreated patients developed tardive dyskinesia compared with less than $5 \%$ in the risperidone-treated group, even though the latter had significantly more extrapyramidal symptoms at baseline. ${ }^{105}$ Given the well-documented risk factors for tardive dyskinesia, which include older age, female gender and neurodegenerative disorders, ${ }^{106}$ this potential advantage appears clinically significant.

In summary, antipsychotics are the best studied medication for the treatment of BPSD, appear modestly but consistently effective and have significant potential side effects. The newer, atypical antipsychotics, especially risperidone and olanzapine, in low doses appear equally effective but better tolerated with a lower risk of tardive dyskinesia compared with the older typical antipsychotics and should therefore be considered first-line therapies for agitation, particularly in the presence of aggression and psychosis.

\section{Antidepressants}

Antidepressants (Table 2) have been studied for a variety of indications in patients with dementia, including the treatment of agitation, aggression, depression and cognitive enhancement. The treatment of depression and cognitive enhancement is covered by other guidelines and will not be dealt with here.

Trazodone is a triazolopyridine antidepressant, the use of which in the treatment of BPSD has been described in multiple case series and case reports. Reviewing the early reports, Schneider and Sobin ${ }^{107}$ noted nine of 23 dementia patients improved with dosages of 150 to $500 \mathrm{mg}$ per day, with side effects such as sedation and orthostatic hypotension common. In several more recent uncontrolled trials and series, high rates of improvement were noted in agitation, restlessness, anxiety, irritability and emotional lability at a variety of dosages, including doses as low as $25 \mathrm{mg}$ t.i.d. and $50 \mathrm{mg}$ q.h.s. ${ }^{108-111}$ Unfortunately, there are only two, randomized, controlled trials, the design of which do not allow for definitive conclusions about the role of trazodone for BPSD. In a small, placebo-controlled, double-blind, crossover trial, ten AD patients were treated with trazodone (maximum dose $50 \mathrm{mg}$ t.i.d.), buspirone, or a placebo. ${ }^{112}$ Trazodone-treated patients had small but significant improvements compared with buspirone and placebo, though some could not tolerate $150 \mathrm{mg}$ per day because of excess sedation. In a recent, randomized, double-blind trial of 28 patients with dementia, half were treated with trazodone (average dose $218 \mathrm{mg}$ ) and half with haloperidol (average dose $2.5 \mathrm{mg}) .{ }^{113}$ While both groups improved equally as measured by changes in an agitation scale, adverse events and dose reductions occurred in $14 \%$ and $29 \%$ of trazodone patients compared with $50 \%$ and $57 \%$ of haloperidol-treated patients. Lack of a placebo control group limits definitive statements about the results of this study.

The use of selective serotonin re-uptake inhibitors (SSRIs) for the treatment of BPSD has received increasing attention with some investigators even recommending them as first-line agents. ${ }^{114}$ In a series of $10 \mathrm{AD}$ patients treated with fluoxetine, there was significant improvement in irritability, anxiety, fear and mood lability. ${ }^{115}$ While fluoxetine was well-tolerated in that series, another description of five patients suggested that fluoxetine was ineffective and caused significant side effects, including confusion, agitation, dizziness, nausea, anorexia, weight loss and insomnia. ${ }^{116}$ In a recent series of 20 patients (19 treated with sertraline $50 \mathrm{mg}$, one treated with paroxetine 20 $\mathrm{mg}$ ), 15 patients were rated as moderately or markedly improved. The medication was well-tolerated with only one patient requiring discontinuation due to diarrhoea. ${ }^{117}$ In a double-blind, placebo-controlled trial of fluvoxamine in 46 patients with dementia, there were no statistically significant differences, though trends were noted favouring the fluvoxamine for improvement on a variety of behavioral symptoms. ${ }^{118}$ In a large, well-designed, double-blind, placebo-controlled trial of citalopram in 98 dementia patients, significant improvement was noted in symptoms such as confusion, irritability, anxiety, fear and restlessness in the citalopram group. ${ }^{119}$ Because the patients in this study were only mildly disturbed, Pollack et al ${ }^{120}$ have recently attempted to replicate these results in an open study of 16 patients with moderate to severe psychosis or other behaviour problems. Patients received $20 \mathrm{mg}$ of citalopram with marked improvement noted in nine and significant reduction in symptoms such as disinhibition, agitation, hostility and suspicion. Finally, in a group of patients carefully selected to fulfil criteria for frontotemporal dementia, fluoxetine, sertraline or paroxetine were used to treat a variety of characteristic behavioral disturbances. ${ }^{121}$ Disinhibition and depressive symptoms improved in 67\%, compulsions improved in 64\% and carbohydrate craving improved in $56 \%$ of subjects.

While irreversible mono-amine oxidase inhibitors (MAOIs) and selective MAO-A inhibitors have been examined for the treatment of depression in dementia, selegeline, a selective MAO-B inhibitor, has been reported to improve a variety of other behaviours in dementia as well. A number of case series ${ }^{122-}$ ${ }^{124}$ have demonstrated modest improvements in some behaviours and mild but significant improvements in BPSD were noted in three of four double-blind, placebo-controlled trials. ${ }^{125-128}$ Unfortunately, almost all of these studies used patients with very mild behavioral disturbances and therefore the utility of selegeline in more severely disturbed patients awaits clarification.

In summary, while antidepressants such as trazodone and the SSRIs appear to be well-tolerated and helpful with BPSD such as irritability, anxiety, agitation, aggression and some disinhibition symptoms, randomized, placebo-controlled studies with more severely behaviorally disturbed patients are required.

\section{Anticonvulsants}

A number of case reports, series and uncontrolled trials suggest carbamazepine is useful for the treatment of BPSD (Table 2). In doses of 100-1000 mg per day, a significant percentage of patients responded within two to four weeks and tolerated the medication well. ${ }^{129-133}$ While an early, double-blind, placebo-controlled trial failed to demonstrate efficacy, ${ }^{134}$ this study suffered from numerous methodological problems, which could account for the negative results. ${ }^{64}$ Three placebocontrolled trials of carbamazepine have all been positive. ${ }^{135-137}$ In the most recent study, 51 nursing home residents with significant agitation scores (tension, hostility, uncooperativeness and/or excitement items) were randomized to receive carbamazepine 
(modal doses $300 \mathrm{mg} /$ day) or placebo. ${ }^{137}$ The investigators attempted to reach an optimal carbamazepine dosage with target serum levels of 5-8 $\mu \mathrm{g} / \mathrm{ml}$, similar to the suggested guidelines for the use of carbamazepine in elderly bipolar patients. ${ }^{107}$ Global improvement was noted in $77 \%$ of carbamazepine-treated patients compared with $21 \%$ of those taking placebo, with positive changes in agitation and aggression. While side effects were more common in the carbamazepine-treated patients, there was only one dropout due to side effects. The authors noted that anecdotally there appeared to be more ataxia and disorientation in the carbamazepine group, though no side effect occurred significantly more often compared with placebo.

Based on experience with elderly bipolars which suggests valproic acid is better tolerated and less likely to cause drug interactions than carbamazepine, this agent has recently been examined for use in the treatment of BPSD. In four early case series of 31 patients with dementia and agitation, nine improved significantly and eight others experienced slight or temporary improvements. ${ }^{138-141}$ In a retrospective review of 25 patients with BPSD, valproic acid was either used alone or was added to ongoing neuroleptic treatment. ${ }^{142}$ Fifty-six per cent of patients were rated as responders and the medication was well-tolerated except for reversible sedation. In a prospective, open study of 16 patients with severe BPSD, significant reductions in agitation scores were noted, with four patients rated at least much improved and four patients as minimally improved. ${ }^{143}$ Valproic acid was generally well-tolerated; adverse events included mild sedation with the medication being discontinued in only one patient because of diarrhoea. These studies utilized divalproex sodium in doses ranging from 500 to $2500 \mathrm{mg}$ per day (average dosages approximately $1500 \mathrm{mg}$ per day), with serum levels of approximately $50 \mathrm{mg} / \mathrm{L}$.

Finally, with the availability of several newer anticonvulsants, drugs such as gabapentin, lamotrigine, clobazam and topiramate will likely be investigated for treatment of BPSD. To date, there are only case reports of patients with BPSD treated with gabapentin. ${ }^{144-148}$ In an open label prospective series, 12 patients were treated with gabapentin for up to eight weeks with an average dose of $900 \mathrm{mg} /$ day. In this antipsychotic-refractory group of mixed dementias there were no significant changes in behavioral scale scores overall, though two patients were rated as much improved and three as minimally improved. ${ }^{149}$ Gabapentin was generally well-tolerated.

In summary, there is increasing interest in the use of anticonvulsants as an alternative to antipsychotics for the treatment of agitation and aggression. At the present time, there are several randomized controlled trials that suggest carbamazepine is effective and well-tolerated but no published controlled trials with other anticonvulsants including valproic acid. Despite the dearth of evidence, a recent survey of North American experts recommended divalproex for the treatment of aggression in dementia and "only modest support" for the use of carbamazepine. ${ }^{150}$

\section{Beta blockers}

The use of propranolol and pindolol to treat BPSD has been reported in several case series and controlled trials (Table 2). ${ }^{151-}$ ${ }^{156}$ While methodological problems, including crossover designs, small numbers and mixed age samples, limit interpretation of results, approximately $67 \%$ of patients appear to respond. ${ }^{157}$ Specific contraindications for the use of beta blockers include congestive heart failure and chronic obstructive pulmonary disease and adverse effects include bradycardia and hypotension (possibly with lesser frequency when using pindolol). These studies have tended to use high dosages (200-800 mg per day for propranolol, 40-60 mg per day for pindolol) with improvement noted in two to four weeks, ${ }^{157}$ though up to eight weeks may be required for full effect. ${ }^{85}$ In contrast to these recommendations, however, a recent small uncontrolled trial of low dose propranolol (10-80 $\mathrm{mg}$ per day) demonstrated effectiveness in $67 \%$ of patients, often within the first two weeks of treatment. ${ }^{158}$

\section{Benzodiazepines}

Several early, large, placebo-controlled trials of oxazepam demonstrated efficacy greater than placebo, though lack of standardized diagnostic criteria and outcome measures limit interpretation of these results. ${ }^{159-161}$ More recently, several studies have compared the efficacy of a variety of benzodiazepines to neuroleptics. ${ }^{162-165}$ Because of concerns regarding the potential for the development of dependence and tolerance with long-term use, as well as side effects including excessive sedation and falls, clinical recommendations for the use of benzodiazepines has generally been limited to short-term and p.r.n. use for specific sedation, for example, when undergoing a procedure (for example, CT scan, dental work), ${ }^{166}$ though these recommendations are not yet supported by randomized trials. Other recommendations have included using short-acting benzodiazepines (for example, lorazepam, oxazepam), ${ }^{59,85,166}$ though several case reports suggest that the long half-life benzodiazepine, clonazepam, may also be helpful. ${ }^{167-169}$

\section{Buspirone}

Buspirone, a nonbenzodiazepine anxiolytic, was first suggested to be useful in the treatment of BPSD in a single case report. ${ }^{170}$ Three uncontrolled trials suggested significant improvements in some patients using dosages of 20-40 mg per day. ${ }^{171-173}$ Buspirone was extremely well-tolerated in these trials with only occasional mild sedation and nausea noted. Two randomized, controlled trials have demonstrated opposite results. A small, placebo-controlled, crossover trial of 10 patients was unable to show buspirone $30 \mathrm{mg}$ per day to be better than placebo. ${ }^{12}$ A recent, randomized, double-blind study of buspirone $15 \mathrm{mg}$ per day versus haloperidol $1.5 \mathrm{mg}$ per day in 26 patients demonstrated equal and significant efficacy over a 10week period. ${ }^{174}$ Given the lack of a placebo control in this study, definitive statements about the efficacy of buspirone cannot be made. In both these trials, however, buspirone was welltolerated. While these results raise questions about the efficacy of buspirone for the treatment of BPSD, its benign side effect profile and minimum tendency to interact with other medications argues for further investigation.

\section{Cholinergic medications}

There is increasing evidence and opinion about the relationship between cholinergic dysfunction and BPSD. ${ }^{175}$ In three large, placebo-controlled trials of tacrine, a cholinesterase inhibitor, ${ }^{176-178}$ no improvement was noted in BPSD. A more recent, open study of tacrine, however, did demonstrate 
significant reductions in behavioral disturbances. ${ }^{179} \mathrm{In}$ a doubleblind, crossover trial of two patients with $\mathrm{AD}$, physostigmine, another cholinesterase inhibitor, decreased hallucinations, agitation and delusions to a greater degree than haloperidol, with fewer side effects. ${ }^{180}$ In a randomized, controlled trial, xanomeline, a direct cholinergic agonist, was compared with placebo in 343 patients with mild to moderate AD. ${ }^{181}$ While designed primarily as a cognitive enhancement trial, results indicated dramatic, dose-dependent reductions in such behaviours as shouting, agitation, delusions and hallucinations. In several open-label studies, donepezil treated AD patients demonstrated improvements on a variety of behavioral measures and specific behaviors such as delusions, agitation, anxiety, aggression and disinhibition. ${ }^{182,183}$ Donepezil may also provide significant benefit for patients with LBD, especially for behaviors such as hallucinations, agitation and apathy, though certain side effects such as worsening of parkinsonism and sedation may be more common than in patients with AD. ${ }^{184,185}$ Finally, in a large randomized placebo-controlled trial of the cholinesterase inhibitor metrifonate for mild to moderate $A D$, total behavioral scores improved with a significant improvement in hallucinations. ${ }^{186}$

In summary, while cholinergic therapy appears to be a promising treatment for a variety of behavioral disturbances in $\mathrm{AD}$, the studies published to date have either been case series, or randomized controlled trials with only mildly behaviorally disturbed patients. Recommendations for their use await randomized trials with patients entered specifically with behavioral target symptoms of moderate to marked severity. The role of cholinergic therapy for patients with LBD should also be further explored.

\section{Other somatic treatments}

A large variety of other somatic therapies have been proposed for BPSD, though there has been little research to support widespread use. Lithium carbonate has demonstrated poor effectiveness in the case reports published to date, ${ }^{107}$ though low doses and serum levels may have acted to limit effectiveness. A small number of individual case reports have suggested a variety of hormonal treatments may be effective for sexually aggressive and disinhibited behaviors as well as agitation, including medroxyprogesterone, ${ }^{187}$ conjugated estrogens, diethylstilbestrol, ${ }^{188}$ cyproterone, ${ }^{189}$ and leuprolide. ${ }^{190,191}$ In a recent small randomized, placebo-controlled study, conjugated estrogens were more effective than placebo at reducing aggressive behaviour in 14 male and female patients with moderate to severe dementia. ${ }^{192}$ Benefits were noted as early as the first week of treatment with $0.625 \mathrm{mg}$ and the medication was welltolerated. Larger studies appear warranted. Ondansetron, a selective $5 \mathrm{HT}_{3}$ antagonist, significantly decreased hallucinations, delusions and agitation in two, open-label trials of patients with dementia and Parkinson's disease. ${ }^{193,194}$ In a small, placebo-controlled, crossover study, dronabinol, a chemical component of marijuana, increased body weight in anorexic patients and decreased severity of disturbed behaviour in 15 Alzheimer's patients. ${ }^{195}$ There are two case reports of ECT used for the treatment of screaming as well as agitation in patients with dementia. ${ }^{196,197}$ Controlled trials with these interventions are required.

\section{SUMMARY AND RECOMMENDATIONS}

The behavioral and psychological symptoms of dementia are common, serious problems that impair the quality of life for both patient and caregiver. After appropriate assessments to rule out intercurrent medical illness, adverse drug reactions and other conditions which might cause BPSD, concomitant illness should be optimized and sensory impairment treated, if possible. The safety of the patient and those around him/her must be considered. Target symptoms should be chosen and documented with attention to antecedents and consequences. Nonpharmacological interventions include use of music, light, changes in level of stimulation and behavioral techniques. While large controlled trials of nonpharmacological interventions are lacking, these techniques should usually be attempted prior to initiation of pharmacotherapy. When pharmacotherapy is necessary, choosing the appropriate medication requires consideration of age-related changes that make elderly dementia patients susceptible to adverse effects. Effectiveness should be measured and patients must be monitored for side effects. Medications should be tapered and withdrawn periodically when and if appropriate. Atypical antipsychotics should be considered first-line therapy in view of their well-documented efficacy. Other useful agents that may be effective and better tolerated than antipsychotics include the antidepressant trazodone and the SSRIs, as well as anticonvulsants such as carbamazepine and valproic acid. Trazodone could be considered when a sleep disturbance is the target symptom. Short-term treatment with benzodiazepines such as lorazepam or oxazepam can be considered for use as p.r.n. agents when there are infrequent episodes of agitation or when sedation for a procedure is required. Other pharmacological interventions with medications such as cholinergic medications, conjugated estrogens, beta-blockers and buspirone require further research to elucidate their benefits and risks.

\section{REFERENCES}

1. Finkel SI (ed). Behavioral and psychological signs and symptoms of dementia. Implications for research and treatment. Int Psychogeriatr 1996; 8(suppl 3).

2. American Psychiatric Association: Diagnostic and statistical manual of mental disorders. 4th Ed. Washington (DC): American Psychiatric Association; 1994.

3. NINCDS-ADRDA Work Group. Criteria for the clinical diagnosis of Alzheimer's disease. J Am Geriatr Soc 1985; 33:2-3.

4. Tonkonongy J, Moak GS. Alois Alzheimer on presenile dementia. J Geriatr Psychiatry Neurol 1988; 2:199-206.

5. Rabins PV, Mace NL, Lucas MJ. The impact of dementia on the family. JAMA1982; 248:333-335.

6. Teri L, Rabins P, Whitehouse P, et al. Management of behaviour disturbance in Alzheimer's disease: current knowledge and future direction. Alzheimer Dis Assoc Disord 1992; 6(2):77-88.

7. Rabins PV, Folstein MF. Delirium and dementia. Diagnostic criteria and fatality rates. Br J Psychiatry 1982; 140:194-253.

8. Reisberg B, Borenstein J, Salob SP, et al. Behavioral symptoms in Alzheimer's disease: phenomenology and treatment. J Clin Psychiatry 1987; 48 Suppl. 5:9-15.

9. Merriam AE, Aronson MK, Gaston P. The psychiatric symptoms of Alzheimer's disease. J Am Geriatr Soc 1988; 36:7-12.

10. Teri L, Larson EB, Reifler BV. Behavioral disturbance in dementia of the Alzheimer's type. J Am Geriatr Soc 1988; 36:1-6.

11. Wragg RE, Jeste DV. Overview of depression and psychosis in Alzheimer's disease. Am J Psychiatry 1989; 146(5):577-587.

12. Reisberg B, Ferris SH, de Leon MJ, et al. Global deterioration scale (GDS). Psychopharmacol Bull 1988; 24:661-663. 
13. Kunik ME, Yudofsky SC, Silver JM, et al. Pharmacologic approach to management of agitation associated with dementia. J Clin Psychiatry 1994; 55(2 Suppl.): 13-17.

14. Whall AL, Gillis GL, Yankou D, et al. Disruptive behaviour in elderly nursing home residents: a survey of nursing staff. J Gerontol Nurs 1992; 12:13-17.

15. Zimmer JG, Watson N, Treat A. Behavioral problems among patients in skilled nursing facilities. Am J Public Health 1984; 74(10):1118-1121.

16. Swearer JM, Drachman DA, O'Donnell BF, et al. Troublesome and disruptive behaviours in dementia; relationship to diagnosis and disease severity. J Am Geriatr Soc 1988; 36(9):784-790.

17. Sultzer DL, Levin HS, Mahler ME, et al. Assessment of cognitive, psychiatric and behavioral disturbances in patients with dementia: the neurobehavioral rating scale. J Am Geriatr Soc 1992; 40:549-555.

18. Mega MS, Cummings JL, Foorello T, et al. The spectrum of behavioral changes in Alzheimer's disease. Neurology 1996; 46(1):130-135.

19. Burns A, Jacoby R, Levy R. Psychiatric phenomena in Alzheimer's disease. I: Disorders of thought content. Br J Psychiatry 1990; 157:72-76.

20. Burns A, Jacoby R, Levy R. Psychiatric phenomena in Alzheimer's disease. II: Disorders of perception. Br J Psychiatry 1990; 157:76-81.

21. Burns A, Jacoby R, Levy R. Psychiatric phenomena in Alzheimer's disease. III. Disorders of mood. Br J Psychiatry 1990; 157:81-86.

22. Burns A, Jacoby R, Levy R. Psychiatric phenomena in Alzheimer's disease. IV. Disorders of behaviour. Br J Psychiatry 1990; 157:86-94.

23. Cummings JL, Miller B, Hill MA, Neshkes R. Neuropsychiatric aspects of multi-infarct dementia and dementia of the Alzheimer type. Arch Neurol 1987; 44:389-393.

24. Brun A, Englund B, Gustafson L, et al. Clinical and neuropathological criteria for frontotemporal dementia. J Neurol Neurosurg Psychiatry 1994; 57:416-418.

25. McKeith IG, Galasko D, Wilcock GK, Byrne EJ. Lewy body dementia - diagnosis and treatment. Br J Psychiatry 1995; 167:709-717.

26. Ryden MB. Aggressive behaviour in persons with dementia who live in the community. Alzheimer Dis Assoc Disord 1988; 2(4):342-355.

27. Chenoweth B, Spencer B. Dementia: the experience of family caregivers. Gerontologist 1986; 26:267-272.

28. Steele C, Rovner B, Chase GA, et al. Psychiatric symptoms and nursing home placement of patients with Alzheimer's disease. Am J Psychiatry 1990; 147:1049-1051.

29. Woolf SH, Battista RN, Anderson GM, Longan AG, Wang EEL. Assessing the clinical effectiveness of preventative manoeuvres: analytical principles and systematic methods in reviewing evidence and developing clinical practice recommendations. J Clin Epidemiol 1990; 43:891-905.

30. Patterson CJS, Gauthier S, Bergman H, et al. The recognition, assessment and management of dementing disorders: conclusions from the Canadian Consensus Conference on Dementia. Can Med Assoc J 1999; 160(12 Suppl):1-15.

31. Corbin S, Eastwood R. Sensory deficits and mental disorders of old age: causal or coincidental associations? Psychol Med 1986; 16:251-256.

32. Horowitz A. The relationship between vision impairment and the assessment of disruptive behaviours among nursing home residents. Gerontologist 1997; 37:620-628.

33. Chapman FM, Dickinson J, McKeith I, Ballard C. Association among visual hallucinations, visual acuity and specific eye pathologies in Alzheimer's disease: treatment implications. Am J Psychiatry 1999; 156:1983-1985.

34. Learoyd BM. Psychotropic drugs and the elderly patient. Med J Aust 1972; 1:1131-1133.

35. American Psychiatric Association. Practice guideline for the treatment of patients with Alzheimer's disease and other dementias of late life. Am J Psychiatry 1997; 154 (suppl).

36. Weiner MF, Koss E, Wild KV, et al. Measures of psychiatric symptoms in Alzheimer patients: a review. Alzheimer Dis Assoc Disord 1996; 10(1):20-30.

37. Folstein MF, Folstein SE, McHugh PR. "Mini-Mental State": a practical method for grading the cognitive state of patients for the clinician. J Psychiatr Res 1975; 12:189-198.

38. Cummings JL, Mega M, Gray K, et al. The neuropsychiatric inventory: comprehensive assessment of psychopathology in dementia. Neurology 1994; 44(12):2308-2314.

39. Cohen-Mansfield J, Billig N. Agitated behaviours in the elderly. I. A conceptual review. J Am Geriatr Soc 1986; 34:711-721.

40. Cohen-Mansfield J. Agitated behaviours in the elderly. II. Preliminary results in the cognitively deteriorated. J Am Geriatr Soc 1986; 34:722-727.

41. Nilsson K, Palmerstierna T, Wistedt B. Aggressive behaviour in hospitalized psychogeriatric patients. Acta Psychiatr Scand 1988; 78:172-175.

42. Palmstierna T, Wistedt B. Staff observation aggression scale, SOAS. Presentation and evaluation. Acta Psychiatr Scand 1987; 76:657-663.

43. Beck CK, Shue VM. Interventions for treating disruptive behaviour in demented elderly people. Nurs Clin North Am 1994; 29:143155.

44. Stewart JT. Management of behaviour problems in the demented patient. Am Fam Physician 1995; 52:2311-2317.

45. Burgio L. Interventions for the behavioral complications of Alzheimer's disease: behavioral approaches. Int Psychogeriatrics 1996; 8(Suppl 1):45-52.

46. Opie J, Rosewarne R, O'Connor DW. The efficacy of psychosocial approaches to behavior disorders in dementia: a systematic literature review. Aust NZ J Psychiatry 1999;33:789-799.

47. Bourgeois MS, Burgio LD, Schulz R, et al. Modifying repetitive verbalizations of community-dwelling patients with $\mathrm{AD}$. Gerontologist 1997;37:30-39.

48. Rovner BW, Steele CD, Shuely Y, Folstein MF. A randomized trial of dementia care in nursing homes. J Am Geriatr Soc 1996; 44:713.

49. Cleary TA, Clamon C, Price M, Shullaw G. A reduced stimulation unit: effects on patients with Alzheimer's disease and related disorders. Gerontologist 1988; 28:511-514.

50. Karlsson I, Brane G, Melin E, Nyth AL, Rybo E. Effects of environmental stimulation on biochemical and psychological variables in dementia. Acta Psychiatr Scand 1988; 77:207-213.

51. Casby JA, Holm MB. The effect of music on repetitive disruptive vocalizations of persons with dementia. Am J Occup Ther 1994; 48:883-889.

52. Gerdner L, Swanson L. Effects of individualized music on confused and agitated elderly patients. Arch Psychiatr Nurs 1993; 5:284-291.

53. Goddaer J, Abraham IL. Effects of relaxing music on agitation during meals among nursing home residents with severe cognitive impairment. Arch Psychiatr Nurs 1994; 8:150-158.

54. Ragneskog H, Kihlgren M, Karlsson I, Norberg A. Dinner music for demented patients: analysis of video-recorded observations. Clin Nurs Res 1996; 5:262-277.

55. Burgio L, Scilley K, Hardin JM, Hsu C, Yancey J. Environmental "white noise": an intervention for verbally agitated nursing home residents. J Gerontol 1996; 51B:364-373.

56. Satlin A, Volicer L, Ross V, Herz L, Campbell S. Bright light treatment of behavioral and sleep disturbances in patients with Alzheimer's disease. Am J Psychiatry 1992; 149:1028-1032.

57. Van Someren EJW, Kessler A, Mirmiran M, Swaab DF. Indirect bright light improves circadian rest-activity rhythm disturbances in demented patients. Biol Psychiatry 1997; 41:955-963.

58. Lyketsos CG, Veiel LL, Baker A, Steele C. A randomized, controlled trial of bright light therapy for agitated behaviors in dementia patients residing in long-term care. Int $\mathrm{J}$ Geriatr Psychiatry 1999; 14:520-525.

59. Rapp MS, Flint AJ, Herrmann N, et al. Behavioral disturbances in demented elderly people. Can J Psychiatry 1992; 37:651-657.

60. Vacarro FJ. Application of operant procedures in a group of institutionalized aggressive geriatric patients. Psychol Aging 1988; 3:22-28 
61. Boehm S, Whall AL, Cosgrove KL, Locke JD, Schlenk EA. Behavioral analyses and nursing interventions for reducing disruptive behaviors of patients with dementia. Appl Nurs Res 1995; 8:118-122.

62. Radebaugh TS, Buckholtz N, Khachaturian Z (eds). Behavioral approaches to the treatment of Alzheimer's disease: research strategies. Int Psychogeriatr 1996; 8(Suppl 1).

63. Herrmann N, Lanctôt K, Naranjo C. Behavioural disorders in demented elderly patients: current issues in pharmacotherapy. CNS Drugs 1996; 6(4):280-300.

64. Herrmann N, Lanctôt KL. From transmitters to treatment: the pharmacotherapy of behavioural disturbances in dementia. Can J Psychiatry 1997; 42(suppl 1):51S-64S.

65. Avorn J, Dreyer P, Connelly K, et al. Use of psychoactive medication and the quality of care in rest homes: findings and policy implications of a state-wide study. N Engl J Med 1989; 320:227-232.

66. Hesse K, Driscoll A, Jacobson S. Neuroleptic prescriptions for acutely ill geriatric patients. Arch Intern Med 1993; 153:25812587.

67. Gurwitz JH, Sourerai SB, Avorn J. Improving medication prescribing and utilization in the nursing home. J Am Geriatr Soc 1990; 38:442-452.

68. Lantz MS, Louis A, Lowenstein G, et al. A longitudinal study of psychotropic prescriptions in a teaching nursing home. Am J Psychiatry 1990; 137:1637-1639.

69. Ryden MB. Aggressive behaviour in persons with dementia who live in the community. Alzheimer Dis Assoc Disord 1988; 2:342355.

70. Semla TP, Palla K, Poddig B, et al. Effect of the Omnibus Reconciliation Act 1987 on antipsychotic prescribing in nursing home residents. J Am Geriatr Soc 1994; 42:648-652.

71. Beers MH, Ouslander JG, Rollingher I, et al. Explicit criteria for determining inappropriate medication use in nursing home residents. Arch Intern Med 1991; 151:1825-1832.

72. Naranjo CA, Herrmann N, Mittmann N, et al. Recent advances in geriatric psychopharmacology. Drugs Aging 1995; 7:184-202.

73. Sunderland T, Tariot PN, Cohen RM, et al. Anticholinergic sensitivity in patients with dementia of the Alzheimer type and aged-matched controls. Arch Gen Psychiatry 1987; 44:418-426.

74. Lipowski ZJ. Delirium in the elderly patient. N Eng J Med 1989; 320:578-582.

75. Barton R, Hurst L. Unnecessary use of tranquilizers in elderly patients. Br J Psychiatry 1966; 112:989-990.

76. Raskind MA, Risse SC, Lampe TH. Dementia and antipsychotic drugs. J Clin Psychiatry 1987; 48(suppl):16-18.

77. Risse SC, Cubberly L, Lampe TH, Zemmers R, Raskind MA. Acute effects of neuroleptic withdrawal in elderly dementia patients. J Geriatr Drug Therapy 1987; 2:65-77.

78. Ray WA, Taylor JA, Meador KG, et al. Reducing antipsychotic drug use in nursing homes. A controlled trial of provider education. Arch Int Med 1993; 153:713-721.

79. Purushotam BT, Meador KG, Gideon P, Fought RL, Ray WE. Effects of antipsychotic withdrawal in elderly nursing home residents. J Am Geriatr Soc 1994; 42:280-286.

80. Horwitz GJ, Tariot PN, Mead K, Cox C. Discontinuation of antipsychotics in nursing home patients with dementia. Am J Geriatr Psychiatry 1995; 3:290-299.

81. Salzman C, Fisher J, Nobel K, et al. Cognitive improvement following benzodiazepine discontinuation in elderly nursing home residents. Int J Geriatr Psychiatry 1992; 7:89-93.

82. Devanand DP, Jacobs DM, Tang MX, et al. The course of psychopathologic features in mild to moderate Alzheimer's disease. Arch Gen Psychiatry 1997;54:257-263.

83. Yeager BF, Farnett LE, Ruzicka SA. Management of the behavioral manifestations of dementia. Arch Intern Med 1995; 155:250-260.

84. Peisah C, Brodaty H. Practical guidelines for the treatment of behavioral complications of dementia. Med J Aust 1994; 161:558-563.

85. Yudofsky SC, Silver JM, Hales RE. Pharmacologic management of aggression in the elderly. J Clin Psychiatry 1990; 51(20 Suppl):22S-28S.
86. Lanctôt KL, Best TS, Mittmann N, et al. Efficacy and safety of neuroleptics in behavioral disorders associated with dementia. J Clin Psychiatry 1998;59:550-561.

87. Devanand DP, Marden K, Michaels KS, et al. A randomized, placebo-controlled dose-comparison trial of haloperidol for psychosis and disruptive behaviors in Alzheimer's disease. Am J Psychiatry 1998;155:1512-1520.

88. Sweet RA, Mulsant BH, Pollock BG, et al. Neuroleptic-induced parkinsonism in elderly patients diagnosed with psychotic major depression and dementia of the Alzheimer type. Am J Geriatr Psychiatry 1996; 4:311-319.

89. McShane R, Keene J, Gedling K, et al. Do neuroleptic drugs hasten cognitive decline in dementia? Prospective study with necropsy follow up. Br Med J 1997; 314:266-270.

90. McKeith I, Fairbairn A, Perry R et al. Neuroleptic sensitivity in patients with senile dementia of Lewy body type. Br Med J 1992;305:673-678.

91. Oberholzer AF, Hendriksen C, Monsch AU, et al. Safety and effectiveness of low-dose clozapine in psychogeriatric patients: a preliminary study. Int Psychogeriatr 1992; 4:187-195.

92. Pitner JK, Mintzer JE, Pennypacker LC, et al. Efficacy and adverse effects of clozapine in four elderly psychotic patients. J Clin Psychiatry 1995; 56:180-185.

93. Salzman C, Vaccaro B, Lieff J, et al. Clozapine in older patients with psychosis and behavioral disruption. Am J Geriatr Psychiatry 1995; 3:26-33.

94. Walker Z, Grace J, Overshot R, et al. Olanzapine in dementia with Lewy bodies: a clinical study. Int $\mathrm{J}$ Geriatr Psychiatry 1999; 14:459-466.

95. Solomons K, Geiger O. Olanzapine use in the elderly: a retrospective analysis. Can J Psychiatry 2000;45:151-155.

96. Bymaster FP, Calligaro DO, Falcone, et al. Radioreceptor binding profile of atypical antipsychotic olanzapine. Neuropsychopharmacology 1996;14:87-96.

97. Street J, Clark S, Gannon KS, et al. Olanzapine treatment of psychotic and behavioural symptoms in patients with Alzheimer's disease in nursing care facilities:a double-blind, randomized, placebo-controlled trial. Arch Gen Psychiatry 2000;57:968-967.

98. Schneider L, Arvantis L, Sweitzer D. Quetiapine may reduce hostility in patients with psychosis related to Alzheimer's disease. Am J Geriatr Psychiatry 1999; 7(Suppl):58.

99. Madhusoodanan S, Brenner R, Araujo L, et al. Efficacy of risperidone treatment for psychoses associated with schizophrenia, schizoaffective disorder, bipolar disorder, or senile dementia in 11 geriatric patients: a case series. J Clin Psychiatry 1995;56:514-518.

100. Zarate CA, Baldessarini RJ, Siegel AJ, et al. Risperidone in the elderly: a pharmacoepidemiologic study. J Clin Psychiatry 1997; 58:311-317.

101. Goldberg RJ, Goldberg J. Risperidone for dementia-related disturbed behaviour in nursing home residents: a clinical experience. Int Psychogeriatr 1997; 9:65-68.

102. Herrmann N, Rivard MF, Flynn M, et al. Risperidone for the treatment of behavioral disturbances in dementia. J Neuropsychiatry Clin Neurosci, in press.

103. Katz IR, Jeste DV, Mintzer JE, et al. Comparison of risperidone and placebo for psychosis and behavioral disturbances associated with dementia: a randomized, double-blind trial. J Clin Psychiatry 1999;60:107-115.

104. De Deyn PP, Rabheru K, Rasmussen A, et al. A randomized trial of risperidone, placebo and haloperidol for behavioral symptoms of dementia. Neurology 1999; 53:946-955.

105. Jeste DV, Lacro JP, Bailey A, et al. Lower incidence of tardive dyskinesia with risperidone compared with haloperidol in older patients. J Am Geriatr Soc 1999;47:716-719.

106. Latimer PR. Tardive dyskinesia: a review. Can J Psychiatry 1995; 40(2 suppl):49-54.

107. Schneider LS, Sobin PB. Nonneuroleptic medications in the management of agitation in Alzheimer's disease and other dementia: a selective review. Int J Geriatr Psychiatry 1991; 6:691-708. 
108. Aisen PS, Johannessen JD, Marin DB. Trazodone for behavioral disturbances in Alzheimer's disease. Am J Geriatr Psychiatry $1993 ; 2: 349-350$.

109. Houlihan DJ, Mulsant BH, Sweet RA, et al. A naturalistic study of trazodone in the treatment of behavioral complications of dementia. Am J Geriatr Psychiatry 1994; 2:78-85.

110. Lebert F, Pasquier F, Petit H. Behavioral effects of trazodone in Alzheimer's disease. J Clin Psychiatry 1994; 55:536-538.

111. Tejera CA, Saravoy SM. Treatment of organic personality syndrome with low-dose trazodone. J Clin Psychiatry 1995; 56:374-375

112. Lawlor BA, Radcliffe J, Molchan SE, et al. A pilot placebocontrolled study of trazodone and buspirone in Alzheimer's disease. Int J Geriatr Psychiatry 1994; 9:55-59.

113. Sultzer DL, Gray KF, Gunay I, Berisford MA, Mahler ME. A double-blind comparison of trazodone and haloperidol for treatment of agitation in patients with dementia. Am J Geriatr Psychiatry 1997; 5:60-69.

114. Karlsson I. Pharmacologic treatment of noncognitive symptoms of dementia. Acta Neurol Scand 1996; Suppl 165:101-104.

115. Lebert F, Pasquier F, Petit H. Behavioral effects of fluoxetine in dementia of Alzheimer's type. Int J Geriatr Psychiatry 1994; 9:590-591.

116. Geldmacher DS, Waldman AJ, Doty L, et al. Fluoxetine in dementia of the Alzheimer's type: prominent adverse effects and failure to improve cognition (letter). J Clin Psychiatry 1994; $55: 161$.

117. Burke WJ, Dewan V, Wengel SP, et al. The use of selective serotonin reuptake inhibitors for depression and psychosis complicating dementia. Int J Geriatr Psychiatry 1997; 12:519-625.

118. Olafsson K, Jorgensen S, Jensen HV, et al. Fluvoxamine in the treatment of demented elderly patients: a double-blind placebocontrolled study. Acta Psychiatr Scand 1992; 851:453-456.

119. Nyth AL, Gottfries CG. The clinical efficacy of citalopram in treatment of emotional disturbances in dementia disorders: a Nordic multicentre study. Br J Psychiatry 1990; 157:894-901.

120. Pollock BG, Mulsant BH, Sweet R, et al. An open pilot study of citalopram for behavioral disturbances of dementia. Am J Geriatr Psychiatry 1997; 5:70-78.

121. Swartz JR, Miller BL, Lesser IM, Darby AL. Frontotemporal dementia: treatment response to serotonin selective reuptake inhibitors. J Clin Psychiatry 1997; 58:212-216.

122. Martini E, Pataky I, Szelagy K, et al. Brief information on an early phase II study with deprenyl in demented patients. Pharmacopsychiatry 1987; 20:256-257.

123. Schneider LS, Gleason R, Zemansky MF, et al. A pilot study of low-dose 1-deprenyl in Alzheimer's disease. J Geriatr Psychiatry Neurol 1991; 4:143-148.

124. Goad DL, Davis CM, Liem P, et al. The use of selegiline in Alzheimer's patients with behaviour problems. J Clin Psychiatry 1991; 52:342-345.

125. Tariot PN, Cohen RM, Sunderland T, et al. 1-Deprenyl in Alzheimer's disease: preliminary evidence for behavioral change with monoamine oxidase B inhibition. Arch Gen Psychiatry 1987; 44:427-433.

126. Mangoni A, Grassi MP, Frattola L, et al. Effects of a MAO-B inhibitor in the treatment of Alzheimer's disease. Eur Neurol 1991; 31:100-107.

127. Burke WJ, Roccaforte WH, Wengel SP, et al. 1-Deprenyl in the treatment of mild dementia of the Alzheimer type: results of a 15month trial. J Am Geriatr Soc 1993; 41:1219-1225.

128. Freedman M, Rewilak D, Xerri T, et al. L-deprenyl in Alzheimer's disease: cognitive and behavioral effects. Neurology 1998; 50: 660-668.

129. Gleason RP, Schneider LS. Carbamazepine treatment of agitation in Alzheimer's outpatients refractory to neuroleptics. J Clin Psychiatry 1990; 51:115-118.

130. Leibovici A, Tariot PN. Carbamazepine treatment of agitation associated with dementia. J Geriatr Psychiatry Neurol 1988; 1:110-112.

131. Patterson JF. Carbamazepine for assaultive patients with organic brain disease. Psychosomatics 1987; 28:579-581.
132. Patterson JF. A preliminary study of carbamazepine in the treatment of patients with dementia. J Geriatr Psychiatry Neurol $1988 ; 1: 21-23$

133. Lemke MR. Effects of carbamazepine on agitation in Alzheimer's inpatients refractory to neuroleptics. J Clin Psychiatry 1995; 56:354-357.

134. Chambers CA, Bain J, Rosebottom R, et al. Carbamazepine in senile dementia and overactivity - a placebo controlled double blind trial. International Research Communication System, Medical Sciences 1982; 10:505-506.

135. Tariot PN, Erb R, Leibovici A, et al. Carbamazepine treatment of agitation in nursing home patients with dementia: a preliminary study. J Am Geriatr Soc 1994; 42:1160-1166.

136. Cooney C, Mortimer A, Smith A, et al. Carbamazepine use in aggressive behaviour associated with senile dementia. Int $\mathrm{J}$ Geriatr Psychiatry 1996; 11:901-905.

137. Tariot PN, Erb R, Podgorski CA, et al. Efficacy and tolerability of carbamazepine for agitation and aggression in dementia. Am $\mathbf{J}$ Psychiatry 1998;155:54-61.

138. Mellow AM, Solano-Lopez C, Davis S. Sodium valproate in the treatment of behavioral disturbance in dementia. J Geriatr Psychiatry Neurol 1993; 6:205-209.

139. Sandborn WD, Bendfeldt F, Hamdy R. Valproic acid for physically aggressive behaviour in geriatric patients. Am J Geriatr Psychiatry $1995 ; 3: 239-242$.

140. Sival RC, Haffmans PMJ, Van Gent PP, et al. The effects of sodium valproate on disturbed behaviour in dementia. J Am Geriatr Soc 1994; 42:906-909.

141. Mazure CM, Druss BG, Cellar JS. Valproate treatment of older psychotic patients with organic mental syndromes and behavioral dyscontrol. J Am Geriatr Soc 1992;40:914-916.

142. Narayan M, Nelson JC. Treatment of dementia with behavioral disturbance using divalproex or a combination of divalproex and a neuroleptic. J Clin Psychiatry 1997; 58:351-354.

143. Herrmann N. Valproic acid treatment of agitation in dementia. Can J Psychiatry 1998; 43:69-72.

144. Regan WM, Gordon SM. Gabapentin for behavioral agitation in Alzheimer's disease. J Clin Psychopharmacol 1997; 17:59-60.

145. Sheldon LJ, Ancill RJ, Holliday SG. Gabapentin in geriatric psychiatry patients. Can J Psychiatry 1998;43:422-423.

146. Goldenberg G, Kahaner K, Basavaraju N et al. Gabapentin for disruptive behavior in an elderly demented patient. Drugs Aging 1998;13:183-184

147. Low RA, Brandes M. Gabapentin for the management of agitation. J Clin Psychopharmacol 1999;19:482-483.

148. Roane DM, Feinberg TE, Mecler L, et al. Treatment of dementiaassociated agitation with gabapentin. J Neuropsychiatry Clin Neurosci 2000;12:40-43.

149. Herrmann N, Lanctôt KL, Myszak M. Effectiveness of gabapentin for the treatment of behavioral disorders in dementia. J Clin Psychopharmacol 2000; 20:90-93.

150. Alexapoulos GS, Silver JM, Kahn DA, et al(eds). Treatment of agitation in older persons with dementia: the expert consensus guideline series. Postgrad Med 1998;26.

151. Petri WM, Ban TA. Propranolol in organic agitation (letter). Lancet $1981 ; 1: 324$

152. Greendyke RM, Schuster DB, Wooton JA. Propranolol in the treatment of assaultive patients with organic brain disease. J Clin Psychopharmacol 1984; 4:282-285.

153. Greendyke RM, Kanter DR, Schuster DB, et al. Propranolol treatment of assaultive patients with organic brain disease. J Nerv Ment Dis 1986; 174:290-294.

154. Greendyke RM, Kanter DR. Therapeutic effects of pindolol on behavioral disturbances associated with organic brain disease: a double-blind study. J Clin Psychiatry 1986; 47:423-426.

155. Greendyke RM, Berner JP, Webster JC, et al. Treatment of behavioral problems with pindolol. Psychosomatics 1989; 30:161-165.

156. Weiler PG, Mugas D, Bernick C. Propranolol for the control of disruptive behaviour in senile dementia. J Geriatr Psychiatry Neurol 1988; 226-230.

157. Smith DA, Perry PJ. Non-neuroleptic treatment of disruptive 
behviour in organic mental syndromes. Ann Pharmcother 1992; 26:1400-1408.

158. Shankle WR, Nielson KA, Cotman CW. Low-dose propranolol reduces aggression and agitation resembling that associated with orbitofrontal dysfunction in elderly demented patients. Alzheimer Dis Assoc Disord 1995; 4:233-237.

159. Beber CR. Management of behaviour in the institutionalized aged. Dis Nerv Sys 1965; 26:591-595.

160. Chesrow EJ, Kaplitz SE, Vetra H, et al. Blind study of oxazepam in the management of geriatric patients with behavioral problems. Clin Med 1965; 71:1001-1005.

161. Sanders JF. Evaluation of oxazepam and placebo in emotionally disturbed aged patients. Geriatrics 1965; 20:739-746.

162. Kirven LE, Montero EF. Comparison of thioridazine and diazepam in the control of nonpsychotic symptoms associated with senility: double-blind study. J Am Geriatr Soc 1973; 21:546-551.

163. Covington JS. Alleviating agitation, apprehension and related symptoms in geriatric patients: a double-blind comparison of phenothiazine and a benzodiazepine. South Med J 1975; 68:719724.

164. Stotskey B. Multicenter study comparing thioidazine with diazepam and placebo in elderly nonpsychotic patients with emotional and behavioral disorders. Clin Ther 1984; 6:546-549.

165. Coccaro EF, Kramer E, Zemishlany Z, et al. Pharmacologic treatment of noncognitive behavioral disturbances in elderly demented patients. Am J Psychiatry 1990; 147:1640-1645.

166. Stern RG, Duffelmeyer ME, Zemeshlani Z, et al. The use of benzodiazepines in the management of behavioral symptoms in demented patients. Psychiatr Clin North Am 1991; 14:375-384.

167. Frinhar JP, Alvarez WA. Clonazepam treatment of organic brain syndromes in three elderly patients. J Clin Psychiatry 1986; 47:525-526.

168. Smeraski PJ. Clonazepam treatment of multi-infarct dementia. J Geriatr Psychiatry Neurol 1988; 1:47-48.

169. Ginsburg ML. Clonazepam for agitated patients with Alzheimer's disease (letter). Can J Psychiatry 1991; 36:237-238.

170. Colenda CC. Buspirone in treatment of agitated demented patient (letter). Lancet 1988; 2:1169.

171. Herrmann N, Eryavec G. Buspirone in the management of agitation and aggression associated with dementia. Am J Geriatr Psychiatry 1993; 1:249-253.

172. Sakauye KM, Camp CJ, Ford PA. Effects of buspirone on agitation associated with dementia. Am J Geriatr Psychiatry 1993; 1:82-84.

173. Levy MA, Burgio LD, Sweet R, et al. A trial of buspirone for the control of disruptive behaviours in community dwelling patients with dementia. Int J Geriatr Psychiatry 1994; 841-848.

174. Cantillon M, Brunswick R, Molina D, et al. Buspirone vs haloperidol: a double-blind trial for agitation in a nursing home population with Alzheimer's disease. Am J Geriatr Psychiatry 1996; 4:263-267.

175. Cummings JL. Cholinesterase inhibitors: a new class of psychotropic compounds. Am J Psychiatry 2000;157:4-15.

176. Farlow M, Gracon SI, Hershey LA, et al. A controlled trial of tacrine in Alzheimer's disease. JAMA1992; 268:2523-2529.

177. Davis KL, Thal LJ, Gamzu ER, et al. A double-blind placebo controlled multicentre study of tacrine for Alzheimer's disease. $\mathrm{N}$ Engl J Med 1992; 327:1253-1259.

178. Knapp MJ, Knopman DS, Solomon PR, et al. A 30-week randomized controlled trial of high-dose tacrine in patients with Alzheimer's disease. JAMA1994; 271:985-991.

179. Kaufer DI, Cummings JL, Christine D. Effect of tacrine on behavioral symptoms in Alzheimer's disease: an open-label study. J Geriatr Psychiatry Neurol 1996; 9:1-6.

180. Cummings JL, Gorman DG, Shapiro J. Physostigmine ameliorates the delusions of Alzheimer's disease. Biol Psychiatry 1993; 33:536-541.

181. Bodick NC, Offen WW, Levey AI, et al. Effects of xanomeline, a selective muscarinic receptor agonist, on cognitive function and behavioral symptoms in Alzheimer's disease. Arch Neurol 1997; 54:465-473.

182. Mega MS, Masterman DM, O'Connor SM, et al. The spectrum of behavioral responses to cholinesterase inhibitor therapy in Alzheimer's disease. Arch Neurol 1999;56:1388-1393.

183. Cummings JL, Donohue JA, Brooks RL. The relationship between donepezil and behavioral disturbances in patients with Alzheimer's disease. Am J Geriatr Psychiatry 2000;8:134-140.

184. Lanctôt KL, Herrmann N. Donepezil for behavioral disorders associated with Lewy bodies: a case series. Int J Geriatr Psychiatry 2000;15:338-345.

185. Shea C, MacKnight C, Rockwood K. Donepezil for treatment of dementia with Lewy bodies: a case series of nine patients. Int Psychogeriatr 1998;10:229-238.

186. Morris JC, Cyrus PA, Orazem J, et al. Metrifonate benefits cognitive, behavioral and global function in patients with Alzheimer's disease. Neurology 1998;50:1222-1230.

187. Cooper AJ. Medroxyprogestrone acetate (MPA) treatment of sexual acting out in men suffering from dementia. J Clin Psychiatry 1987; 48:368-370.

188. Kyomen HH, Nobel KW, Wei JY. The use of oestrogen to decrease aggressive physical behaviour in elderly men with dementia. J Am Geriatr Soc 1991; 39:1110-1112.

189. Nadal M, Allgulander S. Normalization of sexual behaviour in a female with dementia after treatment with cyproterone. Int J Geriatr Psychiatry 1993; 8:265-267.

190. Rich SS, Ovseiw F. Leuprolide acetate for exhibitionism in Huntington's disease. Mov Disord 1994; 9:353-357.

191. Ott BR. Leuprolide treatment of sexual aggression in a patient with dementia and the kluver-bucy syndrome. Clin Neuropharmacol $1995 ; 18: 443-447$.

192. Kyomen HH, Satlin A, Hennen J, et al. Estrogen therapy and aggressive behavior in elderly patients with moderate-to-severe dementia. Am J Geriatr Psychiatry 1999;7:339-348.

193. Zoldan J, Friedberg G, Goldberg-Stern H, et al. Ondansetron for hallucinosis in advanced Parkinson's disease. Lancet 1993; 341:562-563.

194. Zoldan J, Griedberg G, Lioneh M, et al. Psychosis in advanced Parkinson's disease: treatment with ondansetron, a 5HT3 receptor antagonist. Neurology 1995; 45:1305-1308.

195. Volicer L, Stelly M, Morris J, McLaughlin J, Volicer BJ. Effects of dronabinol on anorexia and disturbed behaviour in patients with Alzheimer's disease. Int J Geriatr Psychiatry 1997; 12:913-919.

196. Carlyle W, Killick L, Ancill R. ECT: an effective treatment in the screaming demented patient. J Am Geriatr Soc 1991; 39:637.

197. Holmberg SK, Tariot PN, Challapalli R. Efficacy of ECT for agitation in dementia. Am J Geriatr Psychiatry 1996; 4:330334. 